\title{
Inclusão da glicerina bruta na dieta de vacas da raça Holandesa sobre o consumo, produção e composição do leite
}

\section{Inclusion of crude glycerin in the diet of dairy cows on intake, milk yield and composition}

\author{
Leidiane Reis Pimentel ${ }^{1 *}$; Marcos Inácio Marcondes ${ }^{2}$; Marcelo Valverde da Silva ${ }^{3}$; \\ Jackson Guimarães Siqueira ${ }^{4}$; Mariana Costa Brahim ${ }^{5}$
}

\begin{abstract}
Resumo
Objetivou-se com este trabalho avaliar o efeito da inclusão da glicerina bruta (GB), corrigida em proteína com um coproduto do beneficiamento do milho, o mazoferm, sobre o consumo, produção e composição do leite de vacas da raça Holandesa. Foram utilizadas 12 vacas da raça Holandesa, distribuídas em três quadrados latinos $4 \times 4$, com produção média de $15 \mathrm{~kg}$ de leite. Os animais foram alimentados com quatro dietas, isoproteicas e isoenergéticas, referentes a quatro proporções de substituição do milho grão (MG) pela mistura GP-80, de 0,33,3, 66,6 e 100\% na base na matéria seca total, que corresponderam respectivamente a $0,40,80$ e $120 \mathrm{~g}$ de $\mathrm{GB} / \mathrm{kg}$ de matéria seca. As vacas foram ordenhadas mecanicamente duas vezes ao dia, fazendo-se o registro da produção de leite de cada período experimental e coletado uma amostra composta do leite, para avaliação dos teores de lactose, gordura, proteína, extrato seco total e contagem de células somáticas (CCS). Os dados foram submetidos à análise de variância, utilizando-se o procedimento MIXED do programa Statistical Analisys System. O consumo de matéria seca, a produção média de leite e a produção de leite corrigida para $35 \mathrm{~g}$ de gordura/ $\mathrm{kg}$ de leite, não foram afetados $(\mathrm{P}>0,05)$ pela inclusão da mistura GP-80 na dieta. A composição nutricional do leite (gordura, proteína, lactose e extrato seco total) também não foi influenciada pelos tratamentos $(\mathrm{P}>0,05)$. $\mathrm{O}$ uso de glicerina bruta em dietas que atendam as exigências proteicas e energéticas dos animais, não compromete o consumo de matéria seca, produção, composição e qualidade do leite para vacas da raça holandesa de menor produção.
\end{abstract}

Palavras-chave: Isoenergéticas, gordura, matéria seca, milho

\begin{abstract}
The objective of this study was to evaluate the effect of inclusion of crude glycerin (CG), corrected for protein with a byproduct of processing corn, mazoferm, on intake, production and composition of milk from Holstein cows. A total of 12 Holstein cows distributed in three Latin squares $4 \times 4$, with average production of $15 \mathrm{~kg}$. The animals were fed four diets, protein and isocaloric, referring to four levels of replacement of corn grain by mixing PG-80, 0, 33.3, 66.6 and $100.0 \%$ based on the total dry matter, which corresponded respectively to $0,40,80$ and $120 \mathrm{~g}$ of $\mathrm{CG} / \mathrm{kg}$ dry matter. The cows were milked mechanically twice a day, making up the record of milk production of each experimental

\footnotetext{
${ }^{1}$ Mestre em Zootecnia, Universidade Estadual do Sudoeste da Bahia, UESB, Itapetinga, BA. E-mail: leidyrp@yahoo.com.br

${ }^{2}$ Prof. da Universidade Federal de Viçosa, UFV, Viçosa, MG. E-mail: marcos.marcondes@yahoo.com.br

${ }^{3}$ Mestre em Zootecnia, UFV, Viçosa, MG. E-mail: marcelo.valverde@yahoo.com.br

${ }^{4}$ Discente de Graduação em Ciência e Tecnologia de Laticínios, UFV, Viçosa, MG. E-mail: jacksonguimaraes@yahoo.com.br

${ }^{5}$ Discente de Graduação em Zootecnia, UFV, Viçosa, MG. E-mail: marianabrahim@gmail.com

* Autor para correspondência
} 
period and collected a sample of milk for evaluation of lactose, fat, protein, total solids and somatic cell count (SCC). Data were subjected to analysis of variance using the MIXED procedure of the Statistical Analysis System. The dry matter intake, the average milk production and milk production adjusted to 35 $\mathrm{g}$ fat $/ \mathrm{kg}$ milk, were not affected $(\mathrm{P}>0.05)$ by the inclusion of GP- 80 mixture in the diet. The nutritional composition of milk (fat, protein, lactose and total solids) was not affected by treatments $(\mathrm{P}>0.05)$. The use of crude glycerin in diets to meet protein and energy requirements of animals does not compromise the dry matter intake, production, composition and milk quality for cows of low production.

Key words: Isocaloric, fat, dry matter, corn

\section{Introdução}

A crescente preocupação mundial com o meio ambiente, juntamente com a busca por fontes de energia renováveis, coloca o biodiesel no centro das atenções e interesses. Diversos países, dentre eles o Brasil, procuram o caminho do domínio tecnológico desse biocombustível, tanto em nível agronômico como industrial, o que deverá provocar fortes impactos na economia brasileira e na política de inclusão social do país (ABDALLA et al., 2008).

Este combustível é produzido a partir de óleo vegetal ou gordura animal (MA; HANNA, 1999) através de transesterificação e como um dos subprodutos dessa reação há produção de glicerina bruta (DONKIN, 2008)

A produção do biodiesel está significativamente acelerada, uma vez que o governo brasileiro estabeleceu a obrigatoriedade da adição de biodiesel ao combustível de petróleo num percentual de $2 \%$, o chamado B2, mediante a Lei 11.097, de 2005. Em 2013 este percentual se elevou para 5\%, o chamado B5. Com a implantação do B5 a produção de biodiesel no Brasil, até maio de 2013 foi de 1,15 bilhão de litros de biodiesel (ANP, 2011; MME, 2013). O acréscimo da disponibilidade de glicerina no mercado brasileiro, com a implantação do B2, deverá ser da ordem de 60 a 80 mil toneladas por ano e com a introdução do B5 (mistura constituída de 5\% de biodiesel ao diesel) em 2013, a previsão é que esta produção aumente para 150 mil toneladas por ano (ANP, 2011).

A glicerina purificada é um composto valioso industrialmente, no entanto, a purificação pode ser antieconômica e insuficiente para consumir o crescimento projetado na produção mundial de glicerina oriunda da produção de biodiesel. O uso de glicerina bruta na alimentação animal pode ser uma maneira de aumentar a eficiência biológica e financeira da produção de biodiesel (ZACARONI, 2010).

Objetivou-se com este trabalho avaliar o efeito da inclusão da glicerina bruta, corrigida em proteína com um coproduto do beneficiamento do milho, o mazoferm, sobre o consumo, produção e composição do leite de vacas da raça Holandesa.

\section{Material e Métodos}

$\mathrm{O}$ experimento foi conduzido na Unidade de Ensino, Pesquisa e Extensão em Gado de Leite, Departamento de Zootecnia, da Universidade Federal de Viçosa, no período de 3 fevereiro a 6 abril de 2011. Foram utilizadas 12 vacas da raça Holandesa, distribuídas em três quadrados latinos $4 \mathrm{x} 4$, com animais em período de final de lactação. Sendo utilizada silagem de milho como fonte exclusiva de volumoso e os concentrados experimentais foram formulados à base de milho moído fino, farelo de soja, ureia, mistura mineral, glicerina bruta e mazoferm, um resíduo da maceração do milho, chamado comercialmente de mazoferm, produto aquoso de cor que varia entre amarelo escuro a marrom, cheiro agradável, rico em carboidratos não fibrosos e proteína bruta.

O experimento foi constituído por quatro períodos, com duração de 14 dias cada, sendo os dez primeiros dias de adaptação às dietas e os demais para coleta de dados. Os animais foram alimentados 
com quatro dietas experimentais referentes a quatro proporções de substituição do milho grão (MG) pela glicerina bruta corrigida em proteína com coproduto do beneficiamento do milho com $0,33,3,66,6$ e $100 \%$ na base na matéria seca total (MST), que corresponderam respectivamente a $0,40,80$ e $120 \mathrm{~g}$ de $\mathrm{GB} / \mathrm{kg}$ de MST. A glicerina bruta e o mazoferm foram utilizados na dieta como uma mistura (GP80 ), constituindo $80 \%$ de glicerina bruta e $20 \%$ de mazoferm. Por sua constituição em proteína, o mazoferm apresenta potencial para ser utilizado como fonte protéica na formulação de rações. Dessa forma, o mazoferm foi utilizado para ajustar o teor de proteína bruta da dieta, e a GB utilizada como fonte energética, uma vez que, as dietas foram formuladas para serem isoproteicas e isoenergéticas, com $17 \%$ de proteína bruta e $66 \%$ de NDT, de forma a atender as exigências nutricionais de uma vaca de $650 \mathrm{~kg}$ de peso corporal, produzindo $20 \mathrm{~kg} /$ dia de leite com $3,5 \%$ de gordura (NRC, 2001). Na Tabela 1, estão apresentadas as proporções dos ingredientes das dietas experimentais, baseados em valores médios de composição dos alimentos (VALADARES FILHO; PAULINO; MAGALHÃES, 2010). A mistura de microminerais foi balanceada para atender $100 \%$ das exigências nutricionais segundo o NRC (2001).

Tabela 1. Proporção dos ingredientes na dieta total, em porcentagem na matéria natural.

\begin{tabular}{lcccc}
\hline \multirow{2}{*}{\multicolumn{1}{c}{ Ingredientes }} & \multicolumn{3}{c}{ Níveis de substituição do milho grão pela mistura GP-80 (g/kg) } \\
\cline { 2 - 5 } & 0,0 & 333,0 & 666,0 & 100,0 \\
\hline Silagem de milho & 719,5 & 719,5 & 719,5 & 719,5 \\
Farelo de soja & 106,1 & 109,1 & 112,6 & 115,2 \\
Milho grão moído & 133,5 & 89,0 & 44,5 & 0,0 \\
Mistura GP-80 & 0,0 & 43,0 & 86,0 & 129,0 \\
Ureia & 15,4 & 15,3 & 14,9 & 14,8 \\
Sulfato de amônio & 5,10 & 5,0 & 4,9 & 4,9 \\
Sal comum (NaCl) & 4,9 & 3,6 & 2,4 & 1,2 \\
Calcário calcítico & 6,2 & 6,2 & 6,2 & 6,2 \\
Fosfato bicálcico & 5,9 & 5,9 & 5,9 & 5,9 \\
Premix mineral ${ }^{1}$ & 0,57 & 0,57 & 0,57 & 0,57 \\
Vitamina ADE & 3,4 & 3,4 & 3,4 & 3,4 \\
Melaço & 3,4 & 3,4 & 3,4 & 3,4 \\
Monensina sódica & 0,05 & 0,05 & 0,05 & 0,05 \\
\hline
\end{tabular}

${ }^{1}$ Cinza 98\%; 24,19\% de Ca; 0,07\% de K ; 1,29\% de Mg; 70.000 ppm de Mn; 80.000 ppm de Zn; 25.000 ppm de Fe; 20.000 ppm de $\mathrm{Cu} ; 1.000$ ppm de $\mathrm{Co} ; 1.200$ ppm de I; 600 ppm de Se; 0,09\% de $\mathrm{NaCl}$.

Fonte: Elaboração dos autores.

A silagem, a ração concentrada e a mistura GP-80 foram pesadas separadamente e misturadas dentro do cocho dos animais na hora do fornecimento da alimentação. A quantidade de concentrado fornecido era fixa, de acordo com a produção de leite, e o volumoso fornecido a vontade. Os animais foram manejados em confinamento, sendo dois quadrados latinos mantidos em baias do tipo Free Stall individuais, e no tipo Tie Stall um quadrado latino, onde receberam alimentação duas vezes ao dia, às 6:00 e às 15:00 horas.

As amostras de silagem de milho foram secas em estufa com ventilação forçada $\left(55^{\circ} \mathrm{C} / 72\right.$ horas $)$, sendo processadas em moinhos de facas com peneiras de porosidade de $1 \mathrm{~mm}$ para análises químicas. As análises dos teores de MS foram realizadas segundo método descrito em Silva e Queiroz (2002). 
As vacas foram ordenhadas mecanicamente duas vezes ao dia, fazendo-se o registro da produção de leite (PL) de cada período experimental. Por meio de dispositivo acoplado à ordenhadeira foram coletadas amostras de leite, aproximadamente 300 $\mathrm{mL}$, nas ordenhas da manhã e da tarde, fazendose amostras compostas de cada dia de forma proporcional à produção de leite daquele dia. Foi retirada de cada amostra composta uma alíquota (35 mL) sendo acondicionada em frasco plástico com conservante $\left(\right.$ Bronopol $\left.^{\circledR}\right)$, mantidos entre 2 a $6^{\circ} \mathrm{C}$, e encaminhada para o Laboratório de Análises de Leite do Departamento de Zootecnia da Universidade Federal de Viçosa, para avaliação dos teores de lactose, gordura, proteína, extrato seco total através do equipamento MilkoScan ${ }^{\mathrm{TM}}$ Minor, e contagem de células somáticas (CCS) através do equipamento Fossomatic ${ }^{\mathrm{TM}}$ Minor, segundo métodos descritos pelo International Dairy Federation (1996).

Para determinação da acidez titulável, utilizouse $10 \mathrm{~mL}$ da amostra de leite, através de uma pipeta volumétrica, em que o leite foi colocado em um erlemeyer, onde se adicionou 4 a 5 gotas de fenoftaleína e titulou-se com a solução Dornic $(0,111 \mathrm{~N})$, até atingir uma coloração ligeiramente rósea, procedendo a leitura em 30 segundos (BRASIL, 2006).

A produção de leite corrigida para 3,5\% de gordura (PLC) foi calculada segundo Skalan et al. (1992), pela seguinte fórmula: PLC $=[(0,432+$ $0,1625 \times \%$ de gordura do leite $) \times($ produção de leite em $\mathrm{kg} /$ dia)]. Os valores de CCS foram transformados em escore de células somáticas (ECS) através da função $\mathrm{ECS}=\left[\log _{2}(\mathrm{CCS} / 100.000)\right]+3$, descrita por Dabdoub e Shook (1984).

Os dados foram submetidos à análise de variância, utilizando-se o procedimento MIXED do programa Statistical Analisys System, versão 9.2 (SAS, 2008). Os dados foram analisados segundo modelo estatístico:

$$
\begin{aligned}
& \mathrm{Y}_{\mathrm{ijkl}}=\mu+\mathrm{T}_{\mathrm{i}}+\mathrm{Q}_{\mathrm{j}}+\mathrm{P}_{\mathrm{k}}+\mathrm{A}_{(\mathrm{j}) \mathrm{l}}+\mathrm{TQ}_{\mathrm{ij}}+\mathrm{e}_{\mathrm{ijk}} \text {, sendo: } \\
& \mathrm{Y}_{\mathrm{ijkl}}=\text { resposta experimental; } \\
& \mu=\text { constante geral; } \\
& \mathrm{T}_{\mathrm{i}}=\text { efeito fixo relativo ao tratamento } \mathrm{i} ; \\
& \mathrm{Q}_{\mathrm{j}}=\text { efeito aleatório relativo ao quadrado latino } \mathrm{j} ; \\
& \mathrm{P}_{\mathrm{k}}=\text { efeito aleatório relativo ao período } \mathrm{k} ;
\end{aligned}
$$

$A_{(j) !}=$ efeito aleatório do animal 1 aninhado ao quadrado latino $\mathrm{j}$;

$\mathrm{TQ}_{\mathrm{ij}}=$ efeito aleatório da interação entre o tratamento $\mathrm{j}$ e o quadrado latino $\mathrm{i}$; e

$\mathrm{e}_{\mathrm{ijkl}}=$ erro aleatório, associado a cada observação, pressuposto com distribuição Normal $\left(0 ; \sigma^{2}\right)$

Para todas as variáveis testadas, foram avaliados os efeitos lineares e quadráticos do tratamento $\left(\mathrm{T}_{\mathrm{i}}\right)$, sendo considerado o valor de 0,05 como nível crítico de significância.

\section{Resultados e Discussão}

O consumo de matéria seca (CMS), a produção de leite (PL) e a produção de leite corrigida para $3,5 \%$ de gordura, não foram influenciadas pelos tratamentos ( $\mathrm{P}>0,05$, Tabela 2). Com médias de $14,79,15,14$ e 16,66 kg/dia, respectivamente, não havendo diferença entre os níveis de inclusão da mistura GP-80 ( $\mathrm{P}>0,05)$. No presente trabalho as dietas foram formuladas atendendo as exigências nutricionais de uma vaca produzindo $20 \mathrm{~kg} /$ dia de leite. Os animais utilizados estavam em período de final de lactação e a produção foi inferior ao desejável. No entanto, não teve influência dos tratamentos, uma vez que a dieta com a glicerina bruta corrigida em proteína com o produto do beneficiamento do milho foi formulada para ser isoproteica e isoenergética, atendendo as exigências dos animais. 
Tabela 2. Consumo de matéria seca, produção, composição e qualidade do leite em função do nível de substituição do milho grão pela mistura GP-80.

\begin{tabular}{|c|c|c|c|c|c|c|c|}
\hline \multirow[t]{2}{*}{ Item } & \multicolumn{4}{|c|}{$\begin{array}{l}\text { Níveis de substituição do milho grão pela } \\
\text { mistura GP-80 (\%MS) })^{1}\end{array}$} & \multicolumn{2}{|c|}{ Valor - P } & \multirow[t]{2}{*}{$\mathrm{EPM}^{2}$} \\
\hline & 0 & 33,3 & 66,6 & 100 & Linear & Quadrático & \\
\hline CMS (kg/dia) ${ }^{3}$ & 14,66 & 14,71 & 14,94 & 14,84 & 0,473 & 0,601 & 0,172 \\
\hline PL $(\mathrm{kg} / \mathrm{dia})^{4}$ & 15,53 & 15,27 & 15,14 & 14,63 & 0,222 & 0,761 & 0,355 \\
\hline PL 3,5\%G $(\mathrm{kg} / \mathrm{dia})^{5}$ & 16,76 & 16,60 & 16,60 & 16,67 & 0,910 & 0,824 & 0,158 \\
\hline Gordura (\%) & 4,02 & 4,05 & 4,11 & 4,39 & 0,252 & 0,347 & 0,084 \\
\hline Proteína (\%) & 3,20 & 3,17 & 3,20 & 3,27 & 0,211 & 0,252 & 0,031 \\
\hline Lactose (\%) & 4,21 & 4,18 & 4,17 & 4,13 & 0,099 & 0,782 & 0,032 \\
\hline $\operatorname{EST}(\%)^{6}$ & 12,55 & 12,50 & 12,60 & 12,96 & 0,274 & 0,227 & 0,102 \\
\hline $\mathrm{ECS}^{7}$ & 19,26 & 20,00 & 19,56 & 19,39 & 0,998 & 0,235 & 0,227 \\
\hline Acidez $\left({ }^{\circ} \mathrm{D}\right)$ & 17 & 17 & 16 & 17 & 0,509 & 0,250 & 0,002 \\
\hline
\end{tabular}

${ }^{1}$ Mistura GP- $80=$ Mistura de $80 \%$ de glicerina e $20 \%$ de mazoferm; ${ }^{2} \mathrm{EPM}=$ Erro padrão da média; ${ }^{3} \mathrm{CMS}=$ Consumo de matéria seca; ${ }^{4} \mathrm{PL}=$ Produção de leite; ${ }^{5} \mathrm{PL} 3,5 \% \mathrm{G}=$ Produção de leite corrigida para $3,5 \%$ de gordura; ${ }^{6} \mathrm{EST}=$ Extrato seco total; ${ }^{7} \mathrm{ECS}$ = Escore de células somáticas. Corresponde a valores de CCS de 78.395, 131.543, 96.683 e 85.815, para 0, 33,3, 66,6 e 100\% respectivamente.

Fonte: Elaboração dos autores.

Donkin et al. (2009), testando os tratamentos 0, 5,10 e $15 \%$ de inclusão de glicerina na matéria seca das dietas, fornecendo como volumoso a silagem de milho, afirmaram que o glicerol é um substituto adequado para o grão de milho em rações para o gado leiteiro em lactação e que podem ser incluídas em rações para um nível de até $15 \%$ da matéria seca, sem efeitos adversos sobre a produção de leite ou a composição do leite.

Wang et al. (2008), em estudo sobre o efeito da suplementação de vacas Holandesas do quarto ao $63^{\circ}$ dia pós-parto com glicerina purificada $(99,8 \%$ de glicerol), com trinta e seis vacas blocadas por ordem e data do parto, recebendo os tratamentos controle (sem glicerol), baixo glicerol (100 g/dia), médio glicerol (200 g/dia) ou alto glicerol (300 g/ dia) misturado manualmente, fornecido três vezes ao dia, observaram que o consumo de matéria seca e a produção de leite não foram afetados pelos tratamentos.

Donkin e Doane (2007), não encontraram efeito significativo na produção e composição do leite em vacas alimentadas com níveis de até $15 \%$ de glicerol em base da MS, adicionado em substituição ao milho grão nas dietas. Trabalhos onde menores níveis de inclusão de glicerol $(<10 \%$ na MS) foram utilizados, também não encontraram diferença significativa sobre a produção de leite (KHALILI et al., 1997; DeFRAIN et al., 2004; BODARSKI et al., 2005). Estas evidências estão de acordo com o encontrado neste trabalho, em que não houve redução da produção de leite, uma vez que, a inclusão de glicerol foi semelhante (10\% na MS).

A composição nutricional do leite (gordura, proteína, lactose e extrato seco total) não foi influenciada pelos tratamentos $(\mathrm{P}>0,05)$. Os valores médios encontrados foram 4,14, 3,21, 4,17 e $12,65 \%$, respectivamente. Isso devido a pouca influência da dieta na alteração dos percentuais dos mesmos.

De acordo com a Instrução Normativa $N^{\circ} 51$ (BRASIL, 2002), o regulamento para leite cru refrigerado, exige um teor original de gordura, com o mínimo de 3,0\% e para proteína, mínimo de $2,9 \%$. Os resultados obtidos para a porcentagem de gordura e de proteína estão dentro dos padrões exigidos pela legislação vigente. 
Os ruminantes têm a capacidade de utilizar o glicerol como precursor gliconeogênico (CHUNG et al., 2007) para a manutenção dos níveis plasmáticos de glicose, pois grande parte do glicerol, contido na dieta sofre fermentação por microrganismos ruminais, proporcionando elevados níveis de produção de ácidos graxos voláteis no rúmen, principalmente propionato e butirato, que serão utilizados como principais fontes de energia pelo animal (BOYD; WEST; BERNARD, 2009). Quando absorvido diretamente pela parede do rúmen, o glicerol é metabolizado no fígado e direcionado para a gliconeogênese pela ação da enzima glicerol quinase, que o converte em glicose. Parte do glicerol pode ser fermentada, a propionato, no rúmen, que, por sua vez, é metabolizado a oxaloacetato, por meio do ciclo de Krebs, no fígado, e pode ser utilizado para formar glicose pela via gliconeogênica (KREHBIEL, 2008).

De acordo com Krehbiel (2008), aproximadamente $13 \%$ do glicerol que chega ao rúmen desaparecem por passagem com a digesta, $44 \%$ por fermentação e $43 \%$ por absorção pela parede. Baseado em observações in vitro, o microrganismo que mais metabolizou o glicerol foi a Selenomonas e os produtos finais foram propionato, lactato, succinato e acetato. Entretanto, outros produtos da fermentação ruminal de glicerol têm sido relatados. A metabolização ruminal de glicerol, in vitro e in vivo, pode resultar em aumento pequeno na proporção molar de propionato e aumento na concentração de butirato, diferentemente de estudos clássicos onde foi observado apenas o aumento de propionato (JOHNS, 1953; GARTON; LOUGH; VIOQUE, 1961).

Apesar da substituição da fonte principal de carboidrato (milho) importante na formação de glicose, pela glicerina bruta com $80 \%$ de glicerol, as dietas foram balanceadas para serem isoproteicas e isoenergéticas, atendendo as exigências dos animais. Além disso, a fermentação do glicerol no rúmen de acordo com a literatura forma-se principalmente o propionato, que será convertido em glicose, utilizado na síntese do leite na glândula mamária. Dessa forma, não foi observado neste trabalho alteração da composição do leite, possivelmente devido à semelhança dos produtos da fermentação da glicerina bruta e do milho.

Não houve diferença entre os tratamentos ( $\mathrm{P}>0,05)$, para os valores de escore de células somáticas Que foram de 19,26, 20,00, 19,56, 19,39 para os níveis de inclusão 0, 33,3, 66,6 e 100,0\% respectivamente. Equivalente a 78.395, 131.543, 96.683 e 85.815 células/mL, respectivamente.

De acordo com a Instrução Normativa (BRASIL, 2002), que define limites mínimos de qualidade para o leite cru, os limites máximos de CCS hoje é de 750.000 células $/ \mathrm{mL}$, sendo que os valores observados neste experimento estão dentro da legislação vigente.

A contagem de células somáticas tem sido considerada medida padrão de qualidade, pois está relacionado com a composição, rendimento industrial e segurança alimentar (BUENO et al., 2005). O baixo escore de células somáticas encontrado no experimento se deve provavelmente pelo manejo utilizado no experimento, tanto na ordenha quanto nas instalações, evitando processos infecciosos e o aumento da CCS.

Para os valores de acidez titulável, mais uma vez não foi observado efeito dos tratamentos $(\mathrm{P}>0,05)$. Os valores médios para acidez nos níveis de substituição do milho grão pela mistura GP80 de $0,33,3,66,6$ e 100\%, foram de 17, 17, 16 e $17^{\circ} \mathrm{D}$, respectivamente. De acordo com a Instrução Normativa, que define limites mínimos de qualidade para o leite cru, a acidez deve está entre 14 a $18^{\circ} \mathrm{D}$. Assim os valores encontrados neste experimento estão dentro do padrão exigido (BRASIL, 2002).

Segundo a legislação, o leite tem uma acidez natural no instante da ordenha ( $\mathrm{pH}$ entre 6,6 a 6,7 ou 16 a $20^{\circ}$ Dornic). Os valores de acidez encontrado no presente trabalho apresentaram resultados normais, isso possivelmente ao manejo utilizado na ordenha, com higienização adequada. As análises 
também foram realizadas logo após a ordenha, evitando multiplicação dos microrganismos. Não houve diferença entre os tratamentos $(\mathrm{P}>0,05)$, uma vez que, os animais receberam o mesmo manejo de higienização durante a ordenha.

\section{Conclusão}

O uso de glicerina bruta em dietas que atendam as exigências proteicas e energéticas dos animais, não compromete o consumo de matéria seca, produção, composição e qualidade do leite para vacas de baixa produção.

\section{Agradecimentos}

À Universidade Federal de Viçosa, sobretudo ao Departamento de Zootecnia por ter possibilitado a realização deste trabalho.

\section{Referências}

ABDALLA, A. L.; SILVA FILHO, J. C. da; GODOI, A. R. de; CARMO, C. A.; EDUARDO, J. L. P. Utilização de subprodutos da indústria de biodiesel na alimentação de ruminantes. Revista Brasileira de Zootecnia, Viçosa, MG, v. 37, p. 260-258, 2008. Suplemento Especial.

AGÊNCIA NACIONAL DO PETRÓLEO, GÁS NATURAL E BIOCOMBUSTÍVIES - ANP. Resolução $n^{o}$. 42 de 24 de novembro de 2004. Especificação do biodiese. 2011. Disponível em: <http://www.anp.gov. br>. Acesso em: 19 abr. 2011.

BODARSKI, R.; WERTELECKI, T.; BOMMER, F.; GOSIEWSKI, S. The changes of metabolic status and lactation performance in dairy cows under feeding TMR with glycerin (glycerol) supplement at periparturient period. Eletronic Journal of Polish Agricultural Universities, Animal Husbandry, Madison, v. 8, n. 4, p. 1-9, 2005.

BOYD, J.; WEST, J. W.; BERNARD, J. K. Effects of increasing concentrations of dietary glycerol on ruminal environment and digestibility in lactating dairy cows. Journal of Dairy Science, Madison, v. 92, n. 1, p. 88, 2009.

BRASIL. Instrução Normativa $\mathrm{n}^{\circ} 68$, de 12 de dezembro de 2006. Oficializa os métodos analíticos oficiais físicoquímicos, para controle de leite e produtos lácteos, em conformidade com o anexo desta instrução Normativa, determinando que sejam utilizados nos Laboratórios Nacionais Agropecuários. Diário Oficial [da] União, Brasília, DF, 14 dez. 2006. Seção 1. p. 8.

Ministério da Agricultura, Pecuária e

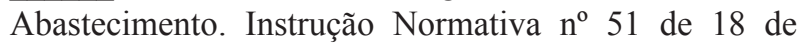
setembro de 2002. Aprova os regulamentos técnicos de produção, identidade e qualidade do leite tipo. Diário Oficial [da] União, Brasília, DF, 20 set. 2002. Seção 1, p. 13.

BUENO, V. F. F.; MESQUITA, A. J.; NICOLAU, E. S.; OLIVEIRA, A. N.; OLIVEIRA, J. P.; NEVES, R. B. S.; MANSUR, J. R. G.; THOMAZ, L. W. Contagem celular somática: relação com a composição centesimal do leite e período do ano no Estado de Goiás. Ciência Rural, Santa Maria, v. 35, n. 4, p. 848-854, 2005.

CHUNG, Y. H.; RICO, D. E; MARTINEZ, C. M.; CASSIDY, T.W.; NOIROT, V.; AMES, A.; VARGA, G. A. Effects of feeding dry glycerin to early postpartum Holstein dairy cows on lactational performance and metabolic profiles. Journal of Dairy Science, Madison, v. 90, n. 8, p. 5682-5691, 2007.

DABDOUB, S. A. M.; SHOOK, G. E. Phenotypic relations among milk yield, somatic cell count, and clinical mastits. Journal of Dairy Science, Madison, v. 67, p. 163-164, 1984. Supplement 1.

DeFRAIN, J. M.; HIPPEN, A. R.; KALSCHEUR, K. F.; JARDON, P. W. Feeding glycerol to transition dairy cows: Effects on blood metabolites and lactation performance. Journal of Dairy Science, Madison, v. 87, n. 12, p. 4195-4206, 2004.

DONKIN, S. S.; KOSER, S. L.; WHITE, H. M.; DOANE, P. H.; CECAVA, M. J. Feeding value of glycerol as a replacement for corn grain in rations fed to lactating dairy cow. Journal of Dairy Science, Madison, v. 92, n. 10, p. 5111-5119, 2009.

DONKIN, S. S.; DOANE, P. Glycerol as a feed ingredient in dairy rations. In: Tri-state dairy nutrition conference. Purdue University, 2007. p. 97-103.

DONKIN, S. S. Glycerol form biodiesel production: the new corn for dairy cattle. Revista Brasileira de Zootecnia, Viçosa, MG, v. 37, p. 280-286, 2008. Suplemento Especial.

GARTON, G. A.; LOUGH, A. K.; VIOQUE, E. Glyceride hidrolysis and glycerol fermentation by sheep rumen contents. Journal of General Microbiology, London, v. 25, p. 215-225, 1961.

INTERNATIONAL DAIRY FEDERATION - IDF. Whole milk. Determination of milkfat, protein and lactose content guide for the operation of mid-infra-red 
instruments. Bruxelas: IDF, 1996. 12 p.

JOHNS, A. T. Fermentation of glycerol in the rumen of the sheep. New Zealand Journal Science Technology, Wellington, v. 35, n. 4, p. 262-269, 1953.

KHALILI, H.; VARVIKKO, T.; TOIVONEN, V.; HISSA, K.; SUVITIE, M. The effects of added glycerol or unprotected free fatty acids or a combination of the two on silage intake, milk production, rumen fermentation and diet digestibility in cows given grass silage based diets. Agricultural Food Science Finland, Jokioinen, v. 6, n. 5-6, p. 349-362, 1997.

KREHBIEL, C. R. Ruminal and physiological metabolism of glycerin. Journal of Dairy Science, Madison, v. 86, n. 4, p. 345-360, 2008.

MA, F.; HANNA, M. A. Biodiesel production: a review. Bioresource Technology, v. 10, n. 1, p. 1-15, 1999.

MINISTÉRIO DE MINAS E ENERGIA - NME. Secretaria de Petróleo, Gás Natural Combustíveis Renováveis. Departamento de Combustíveis Renováveis. Boletim Mensal dos Biocombustíveis Renováveis, Brasília, n. 68, set. 2013. Disponível em: <http://www. anp.gov.br>. Acesso em: 15 jan. 2014.

NATIONAL RESEARCH COUNCIL - NRC. Nutrient requirements of dairy cattle. 7. ed. Washington, DC: National Academy Press, 2001. 381 p.
SILVA, D. J.; QUEIROZ, A. C. Análise de alimentos: métodos químicos e biológicos. 3. ed. Viçosa: UFV, 2002. $235 \mathrm{p}$.

SKALAN, D., ASHKENAZI, R., BRAUN, A.; DEVORN, A. TABORI, K. Fatty acids, calcium soaps of fatty acids, and cottonseeds fed to high yielding cows. Journal of Dairy Science, Madison, v. 75, n. 9, p. 24632472, 1992.

STATISTICAL ANALISYS SYSTEM - SAS. System for microsoft windows. OnlineDoc ${ }^{\circledR}$ for Windows 9.2. Cary: Statistical Analysis System Institute, 2008.

VALADARES FILHO, S. C.; PAULINO, P. V. R.; MAGALHÃES, K. A. Exigências nutricionais de zebuinos e tabelas de composição de alimentos BRCORTE. 2. ed. Viçosa: UFV, DZO, 2010. 142 p.

ZACARONI, O. de F. Resposta de vacas leiteiras à substituição do milho por glicerina bruta. 2010. Dissertação (Mestrado em Ciências Veterinárias) Universidade Federal de Lavras, Lavras.

WANG, C.; LIU, Q.; YANG, W. Z.; HUO, W. J.; DONG, K. H.; HUANG, Y. X.; YANG, X. M.; HE, D.C. Effects of glycerol on lactation performance, energy balance and metabolites in early lactation Holstein dairy cows. Animal Feed Science and Technology, Amsterdam, v. 151, n. 1, p. 12-20, 2008. 